\title{
Inhibition of Nitric Oxide Synthase Does Not Prevent the Induction of Long-Term Potentiation in vivo
}

\author{
D. M. Bannerman, ${ }^{1}$ P. F. Chapman, ${ }^{2}$ P. A. T. Kelly, ${ }^{3}$ S. P. Butcher, ${ }^{1}$ and R. G. M. Morris ${ }^{1}$ \\ Departments of ${ }^{1}$ Pharmacology and ${ }^{2}$ Clinical Neuroscience, Centre for Neuroscience, University of Edinburgh Medical \\ School, Edinburgh EH8 9JZ, Scotland, and ${ }^{3}$ Department of Psychology and Graduate Program in Neuroscience, \\ University of Minnesota, Minneapolis, Minnesota 55455
}

Nitric oxide (NO), a putative intercellular messenger in the CNS, may be involved in certain forms of synaptic plasticity and learning. This articie reports a series of experiments investigating whether an inhibitor of NO synthase, $\boldsymbol{N}_{\omega}$-nitroL-arginine methyl ester (L-NAME), affects long-term potentiation (LTP) in vivo, as the results of recent in vitro experiments would predict. L-NAME, given as an acute injection at a dose sufficient to inhibit hippocampal NO synthase (>90\%), had no effect on perforant path-dentate gyrus LTP induced by a strongly suprathreshold tetanus, but appeared to impair LTP induced by a weak near-threshold tetanus that may be more physiologically relevant. However, subsequent studies revealed that chronic L-NAME treatment ( $>95 \%$ inhibition of NO synthase) had no effect upon LTP induction, and that acute (but not chronic) treatment resulted in a gradual but significant reduction in nontetanized baseline field potentials. The baseline shift appeared to be of a magnitude sufficient to account for the apparent impairment of weak tetanus-induced LTP. This possibility was further examined in a two-hemisphere experiment in which the time course of changes in the field EPSP of the nontetanized pathway served as the within-subject control for the tetanized pathway. No impairment of LTP induction was observed; indeed, if anything, there was a trend for greater potentiation with L-NAME. Because NO has also been implicated in the control of vasodilation, the effect of L-NAME on cerebrovascular function was also investigated. Peripheral blood pressure was significantly increased by L-NAME at the same dose that affected the field EPSP. Local cerebral glucose utilization was unchanged, while local cerebral blood flow decreased significantly in various brain regions, including the hippocampus, indicating an uncoupling of cerebral metabolism and blood flow. Thus, while NO synthase inhibition does not appear to limit the induction of LTP in vivo, it does reduce the size of baseline field EPSPs and affect local cerebrovascular function.

[Key words: nitric oxide, long-term potentiation, hippocampus, rat, cerebrovascular, flow-metabolism coupling]

\footnotetext{
Received Oct. 13, 1993; revised Apr. 15, 1994; accepted Apr. 27, 1994.

This work was supported by an MRC programme grant, a grant from the Human Frontiers Science Panel (R.G.M.M., D.M.B.), the Whitehall Foundation, a McKnight-Land grant professorship (P.F.C.), and a Wellcome Trust project grant

(P.A.T.K.). We thank Roger Spooner for computing software.

Correspondence should be addressed to D. M. Bannerman at the above address.

Copyright (C) 1994 Society for Neuroscience $0270-6474 / 94 / 147415-11 \$ 05.00 / 0$
}

Associative long-term potentiation (LTP) is widely considered to be a model of activity-dependent synaptic plasticity that could be involved in certain forms of learning and memory (Bliss and Lømo, 1973; Morris et al., 1990; Bliss and Collingridge, 1993). The induction of LTP requires the activation of postsynaptic NMDA receptors (Collingridge et al., 1983; Malenka, 1991), and its expression shows a high degree of topological specificity to activated synapses (Kelso et al., 1986; Wigström et al., 1986; Bonhoeffer et al., 1989). However, there is evidence suggesting that the expression of LTP involves an increase in presynaptic transmitter release (Dolphin et al., 1982; Bekkers and Stevens, 1990; Malinow and Tsien, 1990). This implies that there may be an intercellular messenger from postsynaptic to presynaptic neurons.

One candidate intercellular messenger is nitric oxide (NO). $\mathrm{NO}$ has the appropriate properties of being freely diffusable and short-lived, as well as being synthesized by a calcium/calmodulin-dependent enzyme, nitric oxide synthase (Garthwaite et al., 1988; Bredt and Snyder, 1992). Evidence supporting the putative role of $\mathrm{NO}$ as an intercellular messenger has come from experiments demonstrating that administration of NO synthase inhibitors, or of the extracellular NO scavenger hemoglobin, blocks the induction of hippocampal LTP in vitro (Böhme et al., 1991; O'Dell et al., 1991; Schuman and Madison, 1991; Haley et al., 1992). In addition, NO or NO donors (e.g., sodium nitroprusside) can induce synaptic enhancement, either alone (O'Dell et al., 1991; Bon et al., 1992) or when combined with presynaptic activation (Zhuo et al., 1993).

The importance of LTP depends in part on its efficacy as a model of learning and memory. There is evidence suggesting that systemic injection of NO synthase inhibitors affects performance on several different learning tasks (Chapman et al., 1992; Hölscher and Rose, 1992; Böhme et al., 1993). However, it is not known whether inhibitors of NO synthase administered in this way disrupt the establishment of LTP in vivo. This is of great importance when considering the possible use of NO synthase inhibitors as a novel means to investigate the relationship between LTP and learning.

Because NO is involved in several distinct signaling pathways in blood vessels (Moncada, 1992), an investigation of the physiological effects of inhibition of NO synthase in vivo should also include an examination of its effect upon cerebrovascular function. Accordingly, we measured the effects of L-NAME upon blood pressure, local cerebral glucose utilization (LCGU), and local cerebral blood flow (LCBF). 


\section{Materials and Methods}

Electrophysiology. Male hooded Lister rats $(250-450 \mathrm{gm} ; n=129)$ were used as subjects. All rats had ad libitum access to food and water and were maintained on a $12 \mathrm{hr}$ light/dark cycle. The experiments were conducted under urethane anesthesia $(1.5 \mathrm{~g} / \mathrm{kg})$, with the rat mounted in a stereotaxic frame (Kopf) with the skull horizontal. The animal's temperature was monitored by a rectal probe and maintained at 36.2 $\pm 0.2^{\circ} \mathrm{C}$ using an isothermic heating blanket (Harvard Apparatus). Teflon-coated stainless steel electrodes were lowered into the hippocampal formation in order to record positive-going field potentials. A bipolar stimulating electrode was positioned in the angular bundle of the perforant path (AP $=-7.5 \mathrm{~mm}, \mathrm{LAT}=4.1 \mathrm{~mm}$ ) and a monopolar recording electrode $(\mathrm{AP}=-3.8 \mathrm{~mm}, \mathrm{LAT}=2.2 \mathrm{~mm}$ ) in the hilus of the dentate gyrus. The field EPSPs were amplified using a polygraph (Grass Instruments).

After the electrodes were implanted and stable potentials recorded, the animals were given intraperitoneal injections of either drug or saline, in equivalent volumes or, in the case of D-2-amino-5-phosphonopentanoate (D-AP5), an intracerebroventricular infusion. None of the animals had received any prior drug treatment, with the exception of those in experiment 4, which had received chronic injections of L-NAME or saline over a period of 10-20 d. L-NAME (Sigma) and D-NAME (Bachem) were made up at concentrations of $7.5,10$, and $75.0 \mathrm{mg} / \mathrm{ml}$ as appropriate in $0.9 \%$ physiological saline. L-Arginine (Sigma) was made up at a concentration of $225 \mathrm{mg} / \mathrm{ml}$. D-AP5 (Tocris) was made up at a concentration of $100 \mathrm{~mm}$ in equimolar $\mathrm{NaOH}$ and diluted with artificial cerebrospinal fluid (aCSF) to a final concentration of $30 \mathrm{~mm}$.

Perforant path test pulses were generally delivered at low frequency $(0.1$ or $0.05 \mathrm{~Hz}$ ) from a period beginning $20 \mathrm{~min}$ prior to drug infusion through until at least $50 \mathrm{~min}$ after the tetanus, although in some experiments test pulses were omitted until shortly before the start of the baseline period. This stimulation consisted of biphasic pulses at 300 $700 \mu \mathrm{A}$ intensity and $100 \mu \mathrm{sec}$ half-pulse duration. The initial slope of the field EPSP (measured using linear regression between two fixed time points) and the population spike were monitored on line by either a MINC 11/23 or an Acorn A5000 computer running specialized software. One hour after drug administration, animals received either a strong tetanus (consisting of four trains of 33 pulses at $250 \mathrm{~Hz}$, with 10 sec between trains) or a weak tetanus (consisting of three trains of 25 pulses at $100 \mathrm{~Hz}$, with $10 \mathrm{sec}$ between trains) unless otherwise stated. After either tetanus, low-frequency test pulses resumed and responses were monitored for at least $50 \mathrm{~min}$.

In some cases, the experimenter was blind to the drug administered to the animal. There was no difference between the results obtained when the experimenter knew to which group the animal belonged and when the experiment was conducted blind.

Measurement of vascular physiology. A separate group of rats $(n=$ 24) were used for the measurement of either local cerebral glucose utilization (LCGU) or local cerebral blood flow (LCBF). On the day of the experiment, the animals were anesthetized with halothane $(2 \%)$ in a mixture of nitrous oxide (70\%) and oxygen (30\%). Cannulas were inserted into both femoral arteries for the subsequent measurement of arterial blood pressure and the sampling of arterial blood, and into both femoral veins to allow intravenous fluid replacement and injection of radiolabeled tracers for the measurement of either LCGU or LCBF. The incision sites were infiltrated with local anesthetic and the wounds sutured closed. A loose-fitting plaster cast was molded around the animals' hindquarters, leaving free access to the abdomen for subsequent intraperitoneal injections. Thus restrained, the rats were allowed to recover from anesthesia for at least $2 \mathrm{hr}$ before any further experimental manipulation. All preparative surgery was performed by fully trained and experienced personnel and complied with locally approved ethical codes and United Kingdom Home Office regulations.

Measurement of LCBF $(n=12)$ and LCGU $(n=12)$ in hippocampus and cerebellum was performed using fully quantitative ${ }^{14} \mathrm{C}$-iodoantipyrine (Sakurada et al., 1978) and ${ }^{14} \mathrm{C}$-2-deoxyglucose (Sokoloff et al., 1977) autoradiographic techniques, respectively. The protocols were in complete accord with the methodologies as originally described, and previously reported in detail from this laboratory (Sharkey et al., 1991b). The measurement of LCGU was initiated $60 \mathrm{~min}$ after the intraperitoneal injection of L-NAME ( 10 or $75 \mathrm{mg} / \mathrm{kg} ; n=4$ at each dose), and LCBF was measured after $70 \min (n=4$ at each dose). The relative timing of the two measures was in order to ensure that the blood flow measurement (taken over $45 \mathrm{sec}$ ) coincided with the point of median integrated 2-deoxyglucose specific activity in brain tissue (Sharkey et al., 1991a). Control rats were injected with physiological saline $(n=8)$ and equal numbers were used for the measurement of LCGU and LCBF. Arterial blood pressure and rectal temperature were monitored continuously in each animal throughout the study. Samples of arterial blood were withdrawn before the injection of L-NAME or saline and again after $70 \mathrm{~min}$ for the measurement of $\mathrm{pH}, \mathrm{pCO}_{2}, \mathrm{pO}_{2}$, and plasma glucose. At the end of the experimental periods, the rats were killed with an overdose of barbiturate, and the brains dissected intact. Autoradiograms were prepared from coronal sections cut in a cryostat, and a quantitative densitometric analysis of the resultant images performed using a computer-based image analysis system (QUANTIMET 970, Cambridge Instruments).

Nitric oxide synthase assay. NO synthase activity was assayed by measuring the conversion of ${ }^{3} \mathrm{H}$-arginine to ${ }^{3} \mathrm{H}$-citrulline (as previously described by Bredt and Snyder, 1990). Male hooded Lister rats (250$450 \mathrm{gm} ; n=32$ ) were given either a single intraperitoneal injection ( $=18)$ of either $0.9 \%$ physiological saline or L-NAME $(10$ or $75 \mathrm{mg} / \mathrm{kg})$, or a series of 11 intraperitoneal injections $(n=14)$ of either saline or L-NAME $(75 \mathrm{mg} / \mathrm{kg}$ ). One hour after the (last) injection, the rats were killed and their brains removed on ice. Tissue samples from the hippocampus, cerebellum, and cortex were dissected out and homogenized in $10 \mathrm{vol}$ of ice-cold $50 \mathrm{~mm}$ Tris $\mathrm{HCl}, 1 \mathrm{~mm}$ EDTA ( $\mathrm{pH} 7.4$ ). The homogenate was then centrifuged at $10,000 \mathrm{rpm}$ for $1 \mathrm{~min}$ and the supernatant retained on ice. Fifty microliters of the crude supernatant were then incubated for $10 \mathrm{~min}$ in $50 \mathrm{~mm}$ HEPES buffer (pH 7.4), 1 mM NADPH, $1 \mathrm{~mm}$ EDTA, $1.25 \mathrm{~mm} \mathrm{CaCl}_{2}, 1 \mathrm{~mm}$ dithiothreitol, 10 $\mu \mathrm{M}(6 \mathrm{R}) \mathrm{BH}_{4}-2 \mathrm{HCl}, 10 \mu \mathrm{g} / \mathrm{ml}$ calmodulin, $1 \mu \mathrm{M} \mathrm{L}$-arginine, and $0.2 \mu \mathrm{Ci}$ ${ }^{3} \mathrm{H}$-L-arginine in a total volume of $0.15 \mathrm{ml}$ at $37^{\circ} \mathrm{C}$. The reaction was stopped by the addition of $900 \mu$ of stop buffer (10 mM EDTA, 100 mM HEPES; $\mathrm{pH}$ 5.5) and the samples stored on ice. The samples were then loaded onto a $1 \mathrm{ml}$ column of Dowex resin (50X8-200, $\mathrm{Na}^{+}$form) that had previously been equilibrated with stop buffer. The ${ }^{3} \mathrm{H}$-citrulline was eluted with $2 \mathrm{ml}$ of water and quantified by liquid scintillation using Ultima Gold scintillant.

$\mathrm{L}-2,3,4,5-{ }^{3} \mathrm{H}$-Arginine monohydrochloride $(62 \mathrm{Ci} / \mathrm{mmol})$ was obtained from Amersham. (6R)-5,6,7,8-tetrahydro-L-biopterin dihydrochloride [(6R)BII $\left.{ }_{4}-2 \mathrm{IICl}\right]$ was obtained from Semat. Ultima Gold scintillant was obtained from Canberra Packard. All other materials were obtained from Sigma.

\section{Results}

Experiment 1: the effect of L-NAME upon NO synthase activity

L-NAME treatment resulted in a dose-related inhibition of brain NO synthase activity. The results (Fig. 1) are expressed in terms of percentage inhibition relative to control levels of NO synthase activity, measured in tissue samples taken from the relevant saline-injected rats $(n=11)$. A single intraperitoneal injection of $10 \mathrm{mg} / \mathrm{kg} \mathrm{L}-\mathrm{NAME}(n=5)$ resulted in only a partial blockade of enzyme activity (percentage inhibition in hippocampus, 68.2 $\pm 1.7 \%$; cortex, $67.3 \pm 3.1 \%$; cerebellum, $52.6 \pm 1.9 \%$ ). However, a single injection of $75 \mathrm{mg} / \mathrm{kg}$ L-NAME $(n=6)$ resulted in a near-complete inhibition of brain NO synthase (percentage inhibition of synthase activity in hippocampus, $92.9 \pm 1.3 \%$; cortex, $93.0 \pm 1.6 \%$; cerebellum, $89.0 \pm 1.1 \%)$. Chronic intraperitoneal injections of $75 \mathrm{mg} / \mathrm{kg} \mathrm{L-NAME}(n=10)$ resulted in slightly greater inhibition of NO synthase (hippocampus, 96.6 $\pm 0.1 \%$; cortex, $96.6 \% \pm 0.3$; cerebellum, $95.1 \pm 0.6 \%$ ).

\section{Experiment 2: the effect of $L-N A M E$ upon $L T P$ induced by a} strongly suprathreshold tetanus

The induction of LTP was examined in rats given a single intraperitoneal injection of L-NAME $(75 \mathrm{mg} / \mathrm{kg}) 1 \mathrm{hr}$ prior to the LTP-inducing tetanus $(n=8)$. Control animals $(n=8)$ were given an equivalent volume of physiological saline. LTP was induced by a strong tetanic stimulus (consisting of four trains of 33 pulses at $250 \mathrm{~Hz}$ with $10 \mathrm{sec}$ between trains). The mean absolute slope of the pretetanus baseline field EPSPs did not 
$10 \mathrm{mg} / \mathrm{kg} \mathrm{L}-\mathrm{NAME}$

$75 \mathrm{mg} / \mathrm{kg}$ L-NAME (acute)

$75 \mathrm{mg} / \mathrm{kg}$ L-NAME (chronic)

Control

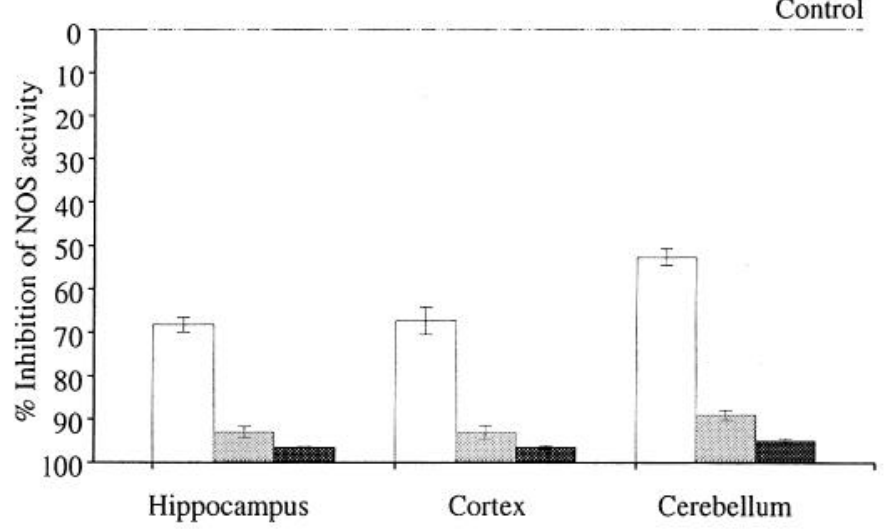

Figure 1. Experiment 1. L-NAME inhibits NO synthase activity. NO synthase activity was determined by measuring the conversion of ${ }^{3} \mathrm{H}$ arginine to ${ }^{3} \mathrm{H}$-citrulline. L-NAME produced a dose-related impairment of NO synthase activity in the brain. NOS activity in saline-injected controls was, in hippocampus, $2.09 \pm 0.21$; cortex, $1.40 \pm 0.11$; and cerebellum, $3.11 \pm 0.25 \mathrm{dpm} \times 10^{5}$.

differ across groups (L-NAME, $75 \mathrm{mg} / \mathrm{kg}=2.94 \pm 0.29 \mathrm{mV} /$ $\mathrm{msec}$; L-NAME, $750 \mathrm{mg} / \mathrm{kg}=3.05 \pm 0.48 \mathrm{mV} / \mathrm{msec}$; saline $=$ $3.46 \pm 0.62 \mathrm{mV} / \mathrm{msec} ; F<1)$. The potentiation elicited by this tetanus was unaffected by L-NAME (Fig. $2 A, B$ ). The mean slope of the field EPSP evoked by $700 \mu \mathrm{A}$ test pulses delivered at 0.1 $\mathrm{Hz}$ and measured between 45 and $50 \mathrm{~min}$ after the tetanus was $121.4 \pm 5.2 \%$ for L-NAME animals, and $121.7 \pm 3.6 \%$ for controls, relative to a baseline averaged over a $5 \mathrm{~min}$ period immediately prior to the tetanus. Animals given $750 \mathrm{mg} / \mathrm{kg}$ of L-NAME $(n=8), 10$ times the initial dose, also demonstrated normal LTP (117.1 $\pm 5.0 \%$; Fig. $2 C$ ). An ANOVA of the LTP in these three groups showed that they did not differ $(F<1)$.

\section{Experiment 3: the effect of L-NAME upon LTP induced by a} just suprathreshold tetanus

In view of the inability of L-NAME to affect LTP induced by strongly suprathreshold tetanic stimuli, we altered the tetanic stimulation parameters to a protocol close to the threshold for LTP induction. The number of tetanic trains, pulses per train, train frequency, and pulse intensity were all reduced until only a minimal but measurable amount of LTP was observed in control animals. The experimental protocol was also changed such that test pulse frequency was reduced to $0.05 \mathrm{~Hz}$ and test pulse intensity to between 300 and $600 \mu \mathrm{A}$ (the intensity required to elicit a response that was $50 \%$ of the maximum EPSP slope). Accordingly, baseline measurements were taken over a 10 min period immediately prior to the tetanus and the amount of potentiation measured between 50 and 60 min post-tetanus.

The mean absolute slope of the baseline field EPSPs did not differ between the L-NAME $(75 \mathrm{mg} / \mathrm{kg} ; 2.86 \pm 0.35 \mathrm{mV} / \mathrm{msec}$; $n=10)$ and saline $(2.75 \pm 0.34 \mathrm{mV} / \mathrm{msec} ; n=7 ; F<1)$ groups. L-NAME had no significant effect on the initial potentiation seen $0-4$ min after the tetanus $(F<1)$ but, if anything, there was greater potentiation in the L-NAME $(121 \pm 3 \%)$ than in the saline group (116 $\pm 3 \%$; Fig. $3 A$ ). The slope of the field EPSP declined in both groups over the course of the next hour. However, this decline was substantially greater in the L-NAME group: (1) the mean slope potentiation 50-60 min post-tetanus shown by the saline group $(110.5 \pm 4.7 \%)$ was significantly greater than that of the L-NAME group $[98.0 \pm 2.9 \% ; F(1,15)$ $=6.26, p<0.025]$; (2) the saline group showed significant potentiation relative to its pretetanus baseline $(t=2.31, \mathrm{df}=$ $6, p<0.05)$ while the L-NAME-treated animals did not $(t<$
A

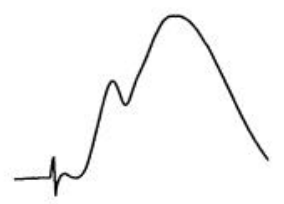

\section{B}

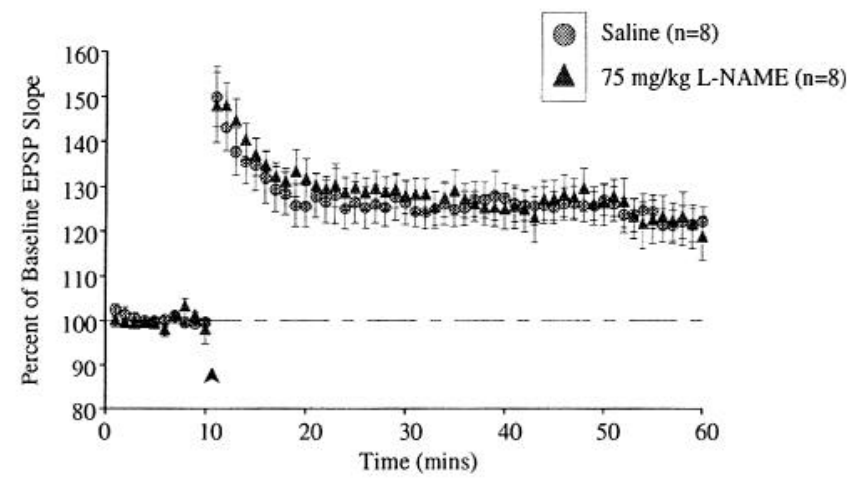

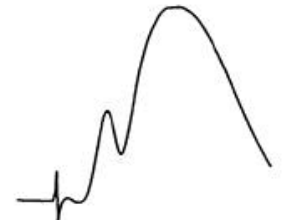

C

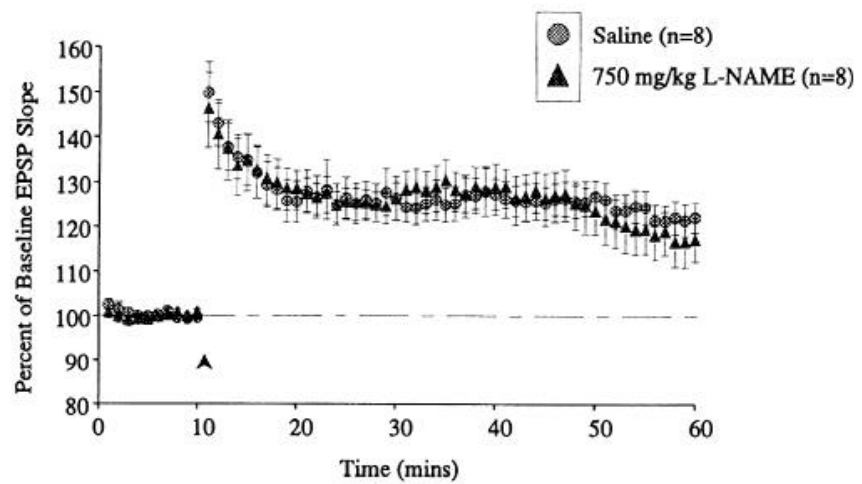

Figure 2. Experiment 2. L-NAME does not affect LTP induced by a strongly suprathreshold tetanus. $A$, Representative field EPSPs recorded from the granule cell layer of the dentate gyrus following perforant path stimulation before (left) and after (right) tetanic stimulation. B, L-NAME (75 $\mathrm{mg} / \mathrm{kg}$ ) does not inhibit the induction of LTP induced by a strongly suprathreshold tetanus. Tetanus given at arrow. $C$, A 10 -fold increase in the dose of L-NAME $(750 \mathrm{mg} / \mathrm{kg})$ was also ineffective. 

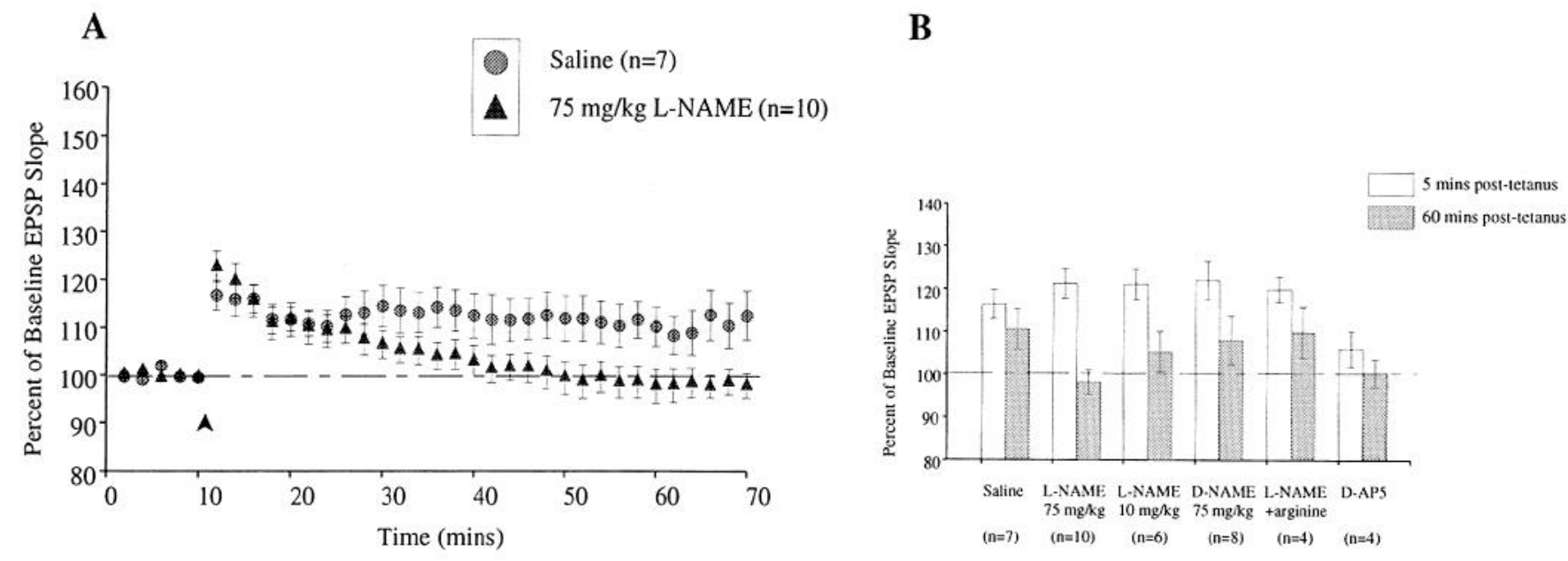

Figure 3. Experiment 3. L-NAME causes an apparent block of LTP induced by a just suprathreshold tetanus. $A, \mathrm{~L}-\mathrm{NAME}$ (75 mg/kg) produces an apparent inhibition of LTP induced by a weak, near-threshold tetanus. $B$, L-NAME $(75 \mathrm{mg} / \mathrm{kg})$ did not affect the amount of potentiation seen $5 \mathrm{~min}$ post-tetanus, but there was a significant difference between $75 \mathrm{mg} / \mathrm{kg} \mathrm{L}-\mathrm{NAME}$ and saline controls 60 min post-tetanus. This effect was dose related, stereoselective, and reversible with coadministration of $225 \mathrm{mg} / \mathrm{kg}$ L-arginine. LTP induced by the weak tetanus was blocked by D-AP5 $(10 \mu$ l, i.c.v., $30 \mathrm{~mm})$.

1); (3) the L-NAME group showed a significantly greater decline in slope between $0-4$ min post-tetanus and $50-60$ min posttetanus $[F(1,15)=10.30, p<0.01]$; and $(4)$ if we define LTP as a $5 \%$ increase over baseline $50-60 \mathrm{~min}$ after the tetanus, only two out of 10 L-NAME-treated animals (20\%) showed LTP, while five of seven saline-treated animals $(71 \%)$ did so $\left(\chi^{2}=\right.$ $4.50, \mathrm{df}=1, p<0.05$ ).

These results raise the possibility that L-NAME may limit the induction of LTP induced by a weak, near-threshold, tetanic stimulus. This effect appears to be dose related, stereospecific, and reversed by coadministration of $\mathrm{L}$ - arginine. A lower dose of L-NAME $(10 \mathrm{mg} / \mathrm{kg})$ resulted in weak potentiation $50-60$ min post-tetanus ( $105.2 \pm 4.8 \% ; n=6$; Fig. $3 B$ ); potentiation comparable to the saline group relative to the baseline was also seen in the D-NAME group $(108.0 \pm 5.6 \% ; n=8)$ and in rats coadministered with both L-NAME $(75 \mathrm{mg} / \mathrm{kg})$ and L-arginine $(225 \mathrm{mg} / \mathrm{kg} ; 109.8 \pm 5.9 \% ; n=4)$.

To investigate whether the potentiation induced by the weak tetanus was NMDA receptor dependent, a further group of animals $(n=4)$ was given an acute intraventricular infusion of D-AP5 $(10 \mu \mathrm{l}$ of $30 \mathrm{~mm}$ in aCSF, infused at $0.05 \mu \mathrm{l} / \mathrm{min}$ over $20 \mathrm{~min}$ ). Both LTP and STP were blocked by AP5 (Fig. 3B).

\section{Experiment 4: the effect of chronic treatment with L-NAME upon induction of LTP by a just suprathreshold tetanus}

In parallel behavioral studies of learning (see preceding article, Bannerman et al., 1994), L-NAME was injected on a daily basis. We were therefore interested to know whether the apparent blockade of weak tetanus-induced LTP in the presence of L-NAME would persist until the end of the behavioral study. Accordingly, a group of animals given daily injections of either L-NAME $(75 \mathrm{mg} / \mathrm{kg} ; n=7)$ or saline $(n=9)$ for 10 to $20 \mathrm{~d}$ (Bannerman et al., 1994; experiments 2 and 3) were also tested for LTP induction by a weak tetanus using the same protocol as that of experiment 3 , including a final injection, under anesthetic, $1 \mathrm{hr}$ prior to tetanization. Surprisingly, no impairment of LTP was observed. The mean absolute slope of the baseline field EPSPs was $2.91 \pm 0.18 \mathrm{mV} / \mathrm{msec}$ (L-NAME) and $3.29 \pm$
$0.39 \mathrm{mV} / \mathrm{msec}$ (saline; $F<1$ ), and the mean potentiation observed 50-60 min post-tetanus was $111.4 \pm 5.4 \%$ (L-NAME) and $113.5 \pm 3.1 \%$ (saline; $F<1$; Fig. 4 ).

\section{Experiment 5: the effect of L-NAME upon an extended $2 \mathrm{hr}$ baseline in the absence of a tetanus}

Repeated difficulties in maintaining stable baselines in L-NAMEtreated rats, coupled with the observation that four of the 10 animals in the L-NAME group of experiment 3 showed field EPSPs that fell at least $5 \%$ below baseline $1 \mathrm{hr}$ post-tetanus, alerted us to the necessity to examine the effects of L-NAME upon an extended baseline covering the full period during which potentiation was being monitored. A further experiment was therefore conducted in which animals were surgically prepared, and then left for a period of at least $1 \mathrm{hr}$ before recording commenced. Following a $20 \mathrm{~min}$ baseline, L-NAME $(75 \mathrm{mg} / \mathrm{kg} ; n$ $=11)$ or saline $(n=9)$ was injected as before. In addition, a further group of rats were given 10 daily injections of L-NAME ( $75 \mathrm{mg} / \mathrm{kg} ; n=6$ ) prior to recording, as well as an L-NAME injection after the $20 \mathrm{~min}$ baseline. Low-frequency test pulses $(0.05 \mathrm{~Hz})$ then continued for a further $120 \mathrm{~min}$ but no tetanus was given.

The mean absolute slope of the baseline field EPSPs prior to drug injection was $3.23 \pm 0.34 \mathrm{mV} / \mathrm{msec}$ (L-NAME, acute), $4.61 \pm 0.71 \mathrm{mV} / \mathrm{msec}$ (L-NAME chronic), and $3.53 \pm 0.28$ $\mathrm{mV} / \mathrm{msec}$ [saline; $F(2,23)=2.91, p>0.05$ ]. However, following injection (Fig. 5), the acutely treated L-NAME rats showed a short-term elevation of the baseline [8-12 min postinjection: acute L-NAME $=107.0 \pm 2.4 \%$; saline $=100.2 \pm 1.6 \% ; F(1,18)$ $=5.15, p<0.05$ ] followed by a long gradual decline, while the saline-treated rats showed a slight but gradual increase. One hour after drug injection, the mean slope of the acutely treated L-NAME rats was $91.3 \pm 3.6 \%$ of baseline, falling to $89.3 \pm$ $4.1 \%$ after $2 \mathrm{hr}$. One hour after injection, the mean slope of the saline-treated rats was $105.4 \pm 1.8 \%$ of baseline, rising to 112.1 $\pm 3.3 \%$ after $2 \mathrm{hr}$. These differences were highly significant both 1 and $2 \mathrm{hr}$ after injection [2 hr: $F(1,18)=17.9, p<0.001]$. Thus, acute L-NAME caused a change in field EPSPs with a 


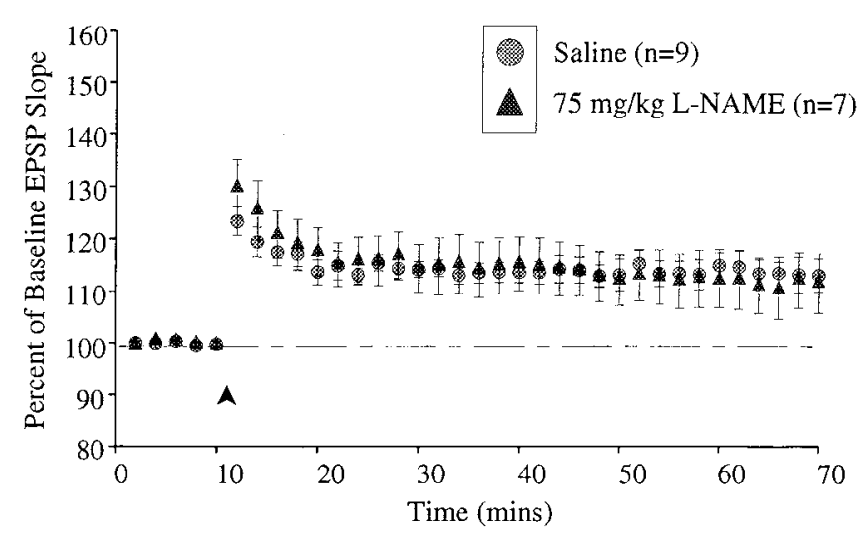

Figure 4. Experiment 4. Chronic treatment (10-20 d) with L-NAME $(75 \mathrm{mg} / \mathrm{kg}$ ) does not block the induction of LTP induced by a just suprathreshold tetanus.

well-defined time course, with most of the decline occurring during the first $60 \mathrm{~min}$ after drug injection. Interestingly, the chronically treated L-NAME group showed neither the shortterm increase immediately after the last injection, nor the gradual decline thereafter (sce Fig. 5). In fact, the time course of the slope changes in this group did not differ from those of the saline-treated group [50-60 $\mathrm{min}, F<1 ; 110-120 \mathrm{~min}, F(1,13)$ $=1.18, p>0.10]$.

For purposes of comparison with previous LTP experiments in this study (e.g., experiments 3 and 4), it is important to measure the change in "baseline" during the second hour starting 60 min postinjection. A further ANOVA was therefore conducted on the acutely treated groups only, comparing the mean slopes 50-60 min postinjection with those 110-120 min postinjection (i.e., equivalent to the analysis used in experiment 3 ). This showed that the slope function for the L-NAME-treated rats declined by $1.7 \pm 3.5 \%$, while the saline-treated rats increased by $6.3 \pm 2.2 \%[F(1,18)=3.46, p=0.08]$. While this change is not significant in itself, the absolute difference between the L-NAME- and saline-treated rats amounts to $8.0 \%$, sufficient to account for the apparent blockade of LTP in expcriment 3. By the same token, the lack of difference in the baseline between the saline- and the chronically treated L-NAME groups, taken together with the results of experiment 4 , is consistent with this account.

\section{Experiment 6: the effect of $L-N A M E$ upon induction of LTP by a weak tetanus using a nontetanized hemisphere as a within-subject control pathway}

In the light of the results of experiment 5 , it is possible that the apparent blockade of weak tetanus LTP (experiment 3 ) can be explained by underlying changes in the baselines. However, experiments 3 and 5 were conducted using separate animals. Accordingly, a two-hemisphere experiment was conducted in which the perforant path of one hemisphere received a weak tetanus while the other served as a within-subject control pathway (Bliss and Lomo, 1973). Animals were prepared in the usual way excepting that stimulating and recording electrodes were implanted bilaterally. The animals were left for $1 \mathrm{hr}$ prior to the start of recording. Potentials were elicited by low-frequency test pulses to each hemisphere $(0.05 \mathrm{~Hz}, 500 \mu \mathrm{A})$, interlaced such that the rats received one stimulus every $10 \mathrm{sec}$. After a $20 \mathrm{~min}$ baseline, they were injected with L-NAME $(75 \mathrm{mg} / \mathrm{kg} ; n=12)$

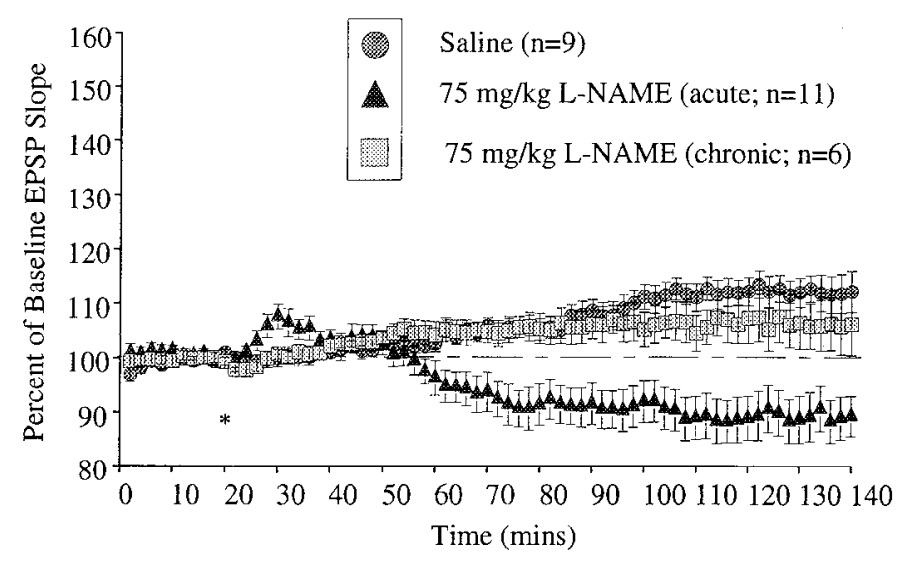

Figure 5. Experiment 5. Acute L-NAME $(75 \mathrm{mg} / \mathrm{kg})$ causes changes in baseline field potentials over an extended $2 \mathrm{hr}$ baseline in the absence of a tetanus. Chronic L-NAME $(75 \mathrm{mg} / \mathrm{kg})$ treatment produced a profile of effect similar to saline-injected animals. Injection at asterisk.

or saline $(n=12)$ and, 60 min later, a weak tetanus was delivered to one hemisphere only. Test pulses continued for a further 60 min. During the course of this study, two reports that intracerebroventricular administration of L-NAME reduced LTP of the dentate population spike were published (Iga et al., 1993; Mizutani et al., 1993). Changes in the amplitude of the population spike can occur for several reasons other than an alteration in synaptic efficacy (McNaughton et al., 1978). Nevertheless, we decided to examine LTP of the population spike in a subset of the animals participating in this study.

There were no significant differences in the mean absolute slope values of the preinjection baselines of the L-NAME- and saline-treated animals, or between the tetanized and nontetanized hemispheres [L-NAME: tetanized $=4.38 \pm 0.51 \mathrm{mV} /$ $\mathrm{msec}$; nontet $=3.47 \pm 0.38 \mathrm{mV} / \mathrm{msec}$; saline: tet $=3.80 \pm 0.35$ $\mathrm{mV} / \mathrm{msec}$; nontet $=3.47 \pm 0.54 \mathrm{mV} / \mathrm{msec}$; groups $F<1$; tet $/$ nontet $F(1,22)=3.20, p>0.05$ ]. All potentials were initially normalized with respect to the preinjection baseline $(10 \mathrm{~min}$ period immediately prior to injection, i.e., $10-20 \mathrm{~min}$ in Fig. $6 A$ ). The first result of note is that over $2 \mathrm{hr}$ L-NAME had an effect upon field EPSPs comparable to that seen in experiment 5 . Figure $6 A$ shows the drug-induced change on what served throughout as the nontetanized control pathway; L-NAME caused an immediate increase in slope followed by a gradual decline, while the saline pathway showed a slow but steady increase. There was a $16.1 \%$ difference between the L-NAME and saline groups at the $80 \mathrm{~min}$ time point on Figure $6 \mathrm{~A}$ (i.e., $60 \mathrm{~min}$ after drug injection and the point at which a tetanus was delivered to the experimental pathway). This difference has to be taken into account to assess the amount of LTP in the two groups-a point shown graphically in Figure 6, $B$ and $C$, which plot the results for both hemispheres in the L-NAME and saline groups, respectively. These graphs appear to show some potentiation in both groups, but it is difficult to assess this quantitatively due to the gradually changing baselines. If one looks solely at the experimental pathway and normalizes with respect to the $10 \mathrm{~min}$ period prior to the tetanus $(70-80 \mathrm{~min})$, the outcome is a result similar to the finding reported in experiment 3: apparently greater potentiation in the saline group (Fig. $6 D$ ). However, if the nontetanized pathway (also normalized with respect to the 70-80 min time period) is used as a within-subject control at each time point $(t)$ throughout the experiment, [i.e., 
A

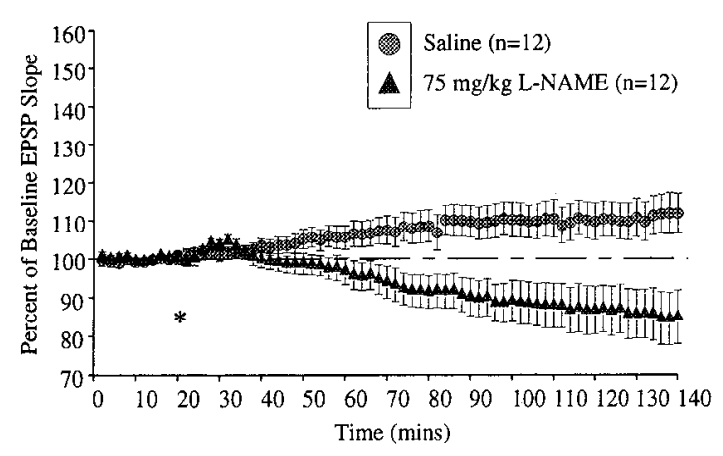

C
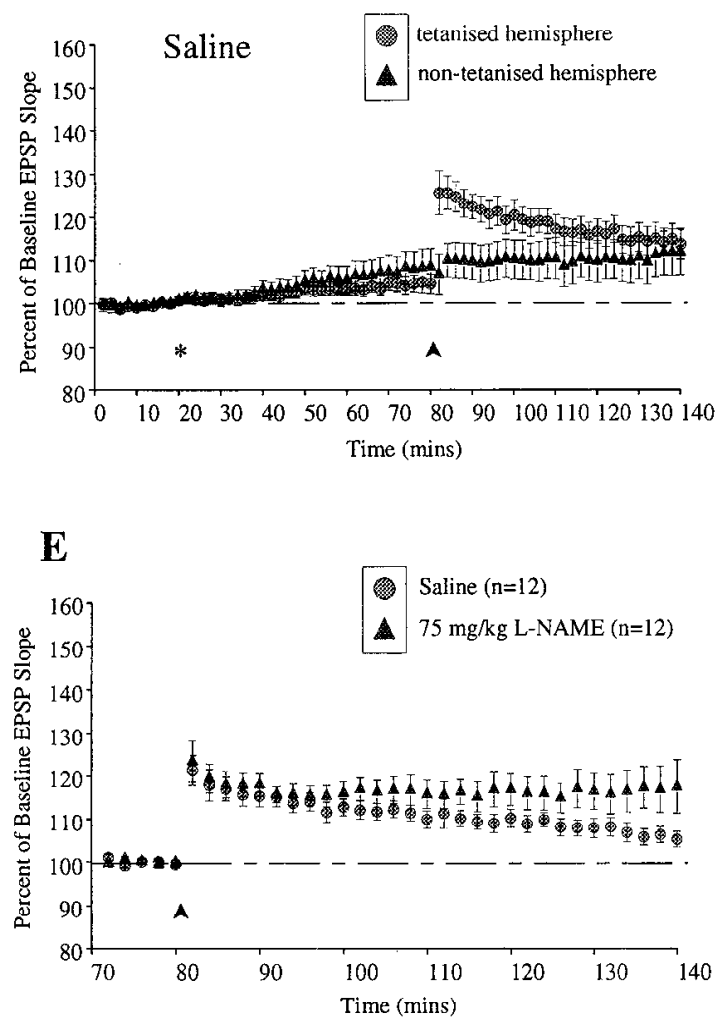

B

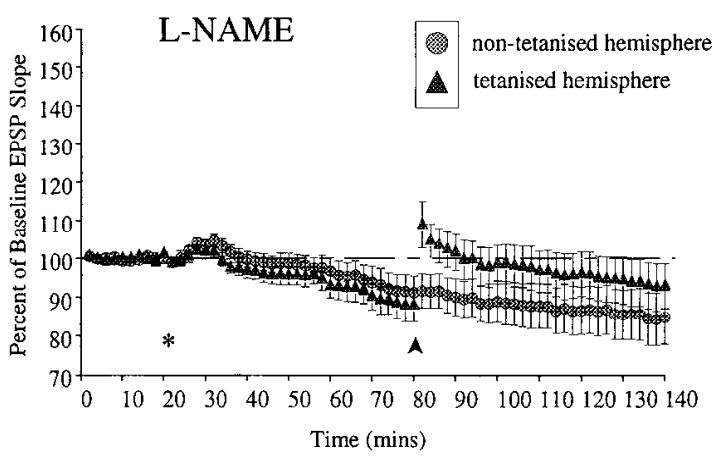

D
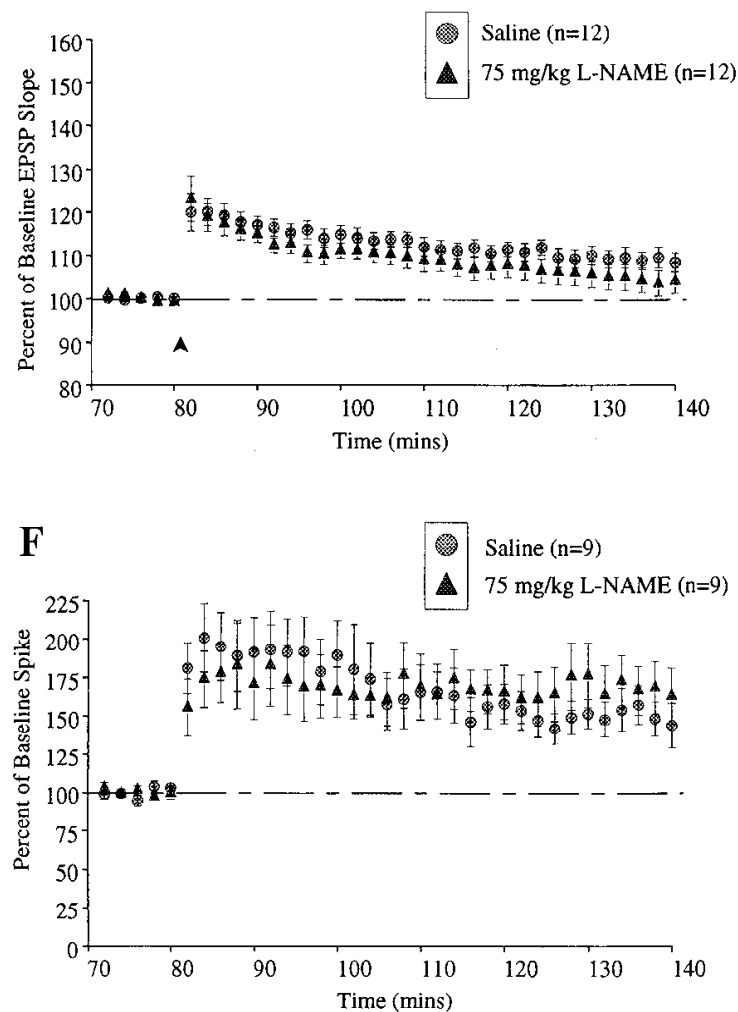

Figure 6. Experiment 6. The effects of $75 \mathrm{mg} / \mathrm{kg}$ L-NAME upon induction of LTP by a weak tetanus using a nontetanized hemisphcre as a withinsubject control pathway. $A$, The effect of L-NAME $(75 \mathrm{mg} / \mathrm{kg})$ and saline on the nontetanized hemisphere (compare with experiment 5$)$. $B$, The effect of L-NAME on the tetanized and nontetanized hemispheres. $C$, The effect of saline on the tetanized and nontetanized hemispheres. $D$, L-NAME $(75 \mathrm{mg} / \mathrm{kg})$ produces a trend toward less LTP induced by a just suprathreshold tetanus, when the data are plotted relative to a withinhemisphere baseline of $10 \mathrm{~min}$ prior to the tetanus (as in experiment 3 ). $E$, L-NAME appears to enhance the amount of potentiation, when the data are plotted using the nontetanized hemisphere as a within-subject control at each time point $(t)$ throughout the experiment [i.e., final value $=\left(\right.$ experimental $t_{t}$ control $\left.\left._{t}\right) \times 100 \%\right] . F$, L-NAME $(75 \mathrm{mg} / \mathrm{kg})$ did not block potentiation of the population spike induced by the weak tetanus, when the data are plotted relative to the $10 \mathrm{~min}$ within-hemisphere baseline prior to the tetanus (i.e., as in $D$ ).

final value ${ }_{t}=\left(\right.$ experimental ${ }_{t} /$ control $\left.\left._{t}\right) \times 100 \%\right]$, a very different result obtains. As shown in Figure $6 E$, it now appears that, if anything, L-NAME is associated with slightly greater potentiation than that shown by the saline group. An ANOVA of the potentiation analyzed in this way at a point $1 \mathrm{hr}$ after the tetanus (i.e., $130-140 \mathrm{~min}$ ) revealed that both groups showed LTP, but there was a trend for there being slightly more in the L-NAME group [L-NAME $=116.8 \pm 5.0 \%$; saline $=106.5 \pm 1.9 \%$; $F(1,22)=3.66,0.10>p>0.05$ ]. It should be noted that our protocol was designed to produce minimal but measurable LTP.
The within-subjects (Fig. $6 E$ ) rather than the between-subjects variability (Fig. $6 C, D$ ) provides the appropriate error term with which to assess the presence or absence of potentiation; relevant ANOVAs comparing the tetanized and nontetanized pathways showed that both groups displayed significant LTP [L-NAME: $F(1,11)=9.42, p<0.01$; saline: $F(1,11)=8.01, p<0.025$ ]

The best extracellular measure of changes in excitatory feedforward synaptic efficacy in the molecular layer of the dentate gyrus is the carly rising slope of the field potential. This is what we have reported throughout this article so far. Nonetheless, 
Table 1. The effects of L-NAME on cerebrovascular function in the awake rat

\begin{tabular}{|c|c|c|c|c|c|c|}
\hline \multirow[b]{3}{*}{ Parameters } & \multirow{2}{*}{\multicolumn{2}{|c|}{ Saline }} & \multicolumn{4}{|l|}{ L-NAME } \\
\hline & & & \multicolumn{2}{|l|}{$10 \mathrm{mg} / \mathrm{kg}$} & \multicolumn{2}{|l|}{$75 \mathrm{mg} / \mathrm{kg}$} \\
\hline & Before & After $1 \mathrm{hr}$ & Before & After $1 \mathrm{hr}$ & Before & After $1 \mathrm{hr}$ \\
\hline Plasma glucose (mg/liter) & $1.57 \pm 0.10$ & $1.53 \pm 0.10$ & $1.52 \pm 0.20$ & $1.42 \pm 0.10$ & $1.55 \pm 0.10$ & $1.31 \pm 0.09$ \\
\hline $\mathrm{pH}$ & $7.38 \pm 0.01$ & $7.38 \pm 0.01$ & $7.35 \pm 0.06$ & $7.39 \pm 0.04$ & $7.41 \pm 0.02$ & $7.41 \pm 0.02$ \\
\hline $\mathrm{pCO}_{2}(\mathrm{~mm} \mathrm{Hg})$ & $40.2 \pm 1.0$ & $39.0 \pm 1.0$ & $39.1 \pm 2.0$ & $41.7 \pm 2.1$ & $42.4 \pm 2.0$ & $38.5 \pm 2.9$ \\
\hline $\mathrm{pO}_{2}(\mathrm{~mm} \mathrm{Hg})$ & $87.2 \pm 2.2$ & $88.8 \pm 3.3$ & $91.7 \pm 3.2$ & $89.8 \pm 2.9$ & $89.4 \pm 3.0$ & $92.6 \pm 2.8$ \\
\hline Mean arterial BP & $131 \pm 5$ & $139 \pm 4$ & $133 \pm 2$ & $160 \pm 4^{*} \dagger$ & $133 \pm 4$ & $173 \pm 8 * \dagger$ \\
\hline
\end{tabular}

There were no significant differences between groups in the physiological status of the animals prior to injection. One hour after the injection of either 10 or $75 \mathrm{mg} / \mathrm{kg}$ L-NAME, mean arterial blood pressure was significantly increased above preinjection levels, and was significantly higher than saline-injected controls. No other physiological variables were significantly altered. Data are presented as mean \pm SEM for $n=4$ in each group, measured immediately before the intraperitoneal injection of either saline of L-NAME, and again $1 \mathrm{hr}$ later.

* Significantly different from preinjection value (Scheffè test).

$\dagger$ Significantly different from the appropriate saline-injected control value (Scheffè test).

following the reports of both Iga et al. (1993) and Mizutani et al. (1993), we also examined LTP of the population spike in a subset of animals participating in this study. To be included, an animal had to have a population spike of $>1 \mathrm{mV}$ pretetanus. The results (Fig. $6 F$ ) indicate that $50-60$ min post-tetanus as much population spike LTP was shown by the L-NAME-treated rats $(166.9 \pm 16.9 \% ; n=9)$ as by the saline group $(150.2 \pm$ $12.3 \% ; n=9)$. These values did not differ $(F<1)$.

\section{Experiment 7: the effect of L-NAME upon cerebrovascular function in the awake rat}

The intraperitoneal injection of both doses of L-NAME resulted in significant incrcases in mcan artcrial blood pressurc (MAPB), which was relatively rapid in onset (within $5 \mathrm{~min}$ ) and was maintained throughout the experimental period (Table 1). Although the higher dose of L-NAME $(75 \mathrm{mg} / \mathrm{kg})$ produced a slightly greater hypertensive response, there was no significant difference in MABP between the two treatment groups. Neither dose of L-NAME significantly altered any of the other physiolugical variables measured (Table 1).

There were no significant changes in LCGU in any of the hippocampal fields measured in this study following either of the two doses of L-NAME. Only in the copula pyramis of the cerebellum was a small but statistically significant decrease in LCGU observed ( $-18 \%)$ following both doses of L-NAME. In contrast, decreases in cerebral blood flow were observed in all hippocampal fields and throughout the cerebellum $70 \mathrm{~min}$ after the injection of L-NAME $(10 \mathrm{mg} / \mathrm{kg})$, although in two areas, cerebellar white matter and the caudal CA1 field of the hippocampus, decreases were not statistically significant. Increasing the dose of L-NAME to $75 \mathrm{mg} / \mathrm{kg}$ had no further effect on LCBF, and there was no significant difference in response between the two doses. Thus, at both doses of L-NAME, and in each of the 19 brain areas analyzed in this study, the ratio of mean LCBF to mean LCGU was decreased (Fig. 7). Such decreases in LCBF in the absence of any changes in LCGU indicate an uncoupling of the fundamental relationship which normally exists between cerebral blood flow and the metabolic demands of brain tissue.

\section{Discussion}

The main findings of this series of experiments were that (1) intraperitoneal injections of L-NAME caused a dose-related inhibition of NO synthase with both a single acute and a series of chronic $75 \mathrm{mg} / \mathrm{kg}$ injections resulting in $>90 \%$ inhibition in hippocampus; (2) L-NAME, at this and a 10-fold higher dose, was without effect upon LTP induced by a strong tetanus and recorded in the dentate gyrus in vivo; (3) L-NAME caused an apparent inhibition of LTP in vivo when induced by a weak tetanus, but subsequent experiments using a within-subject control pathway suggest that this is primarily a consequence of an underlying decrease in the size of the baseline field EPSP; and (4) L-NAME caused a reduction in cerebral blood flow but no change in cerebral glucose utilization.

\section{Has NO synthase been inhibited?}

As the main finding of this report is that an inhibitor of NO synthase, L-NAME, does not appear to block the induction of LTP in vivo induced by either weak or strong tetanic stimuli, it

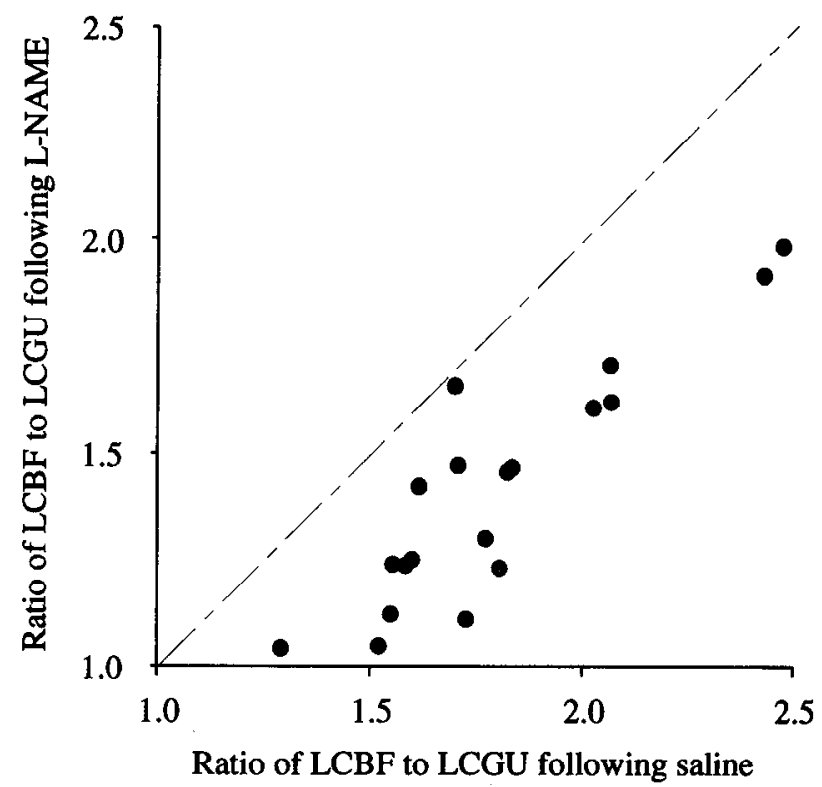

Figure 7. Experiment 7. L-NAME uncouples cerebral blood flow and metabolism. The ratio of local cerebral blood flow to local cerebral glucose metabolism is lower for animals given a single injection of L-NAME $(75 \mathrm{mg} / \mathrm{kg}$ ) than for saline controls. If the flow-metabolism relationship was unchanged by L-NAME, all points (each representing measurements from different subregions of the cerebellum or hippocampus) would fall along the line of identity (illustrated). The shift in the ratios of LCBF to LCGU is indicative of a flow-metabolism uncoupling. 
is essential to establish that the drug administration regimes we used were sufficient to inhibit the enzyme. The results of the NO synthase assay show that a single $75 \mathrm{mg} / \mathrm{kg}$ injection of L-NAME produced a 93\% inhibition of the enzyme in hippocampus. The lower dose of $10 \mathrm{mg} / \mathrm{kg}$ L-NAME resulted in only $68 \%$ inhibition. Dwyer et al. (1991) suggested that a more effective method of inhibiting NO synthase is to give repeated injections of a synthase inhibitor over several days. Their results show that a $50 \mathrm{mg} / \mathrm{kg}$ injection of $\mathrm{L}-\mathrm{N}^{\mathrm{G}}$-nitroarginine (NOArg) caused a $50 \%$ inhibition in cerebellum after a single injection, but $95 \%$ inhibition after $4 \mathrm{~d}$ of twice daily injections. This raised the possibility that an even greater inhibition of NO synthase is obtained with repeated daily injections of L-NAME. Our results following chronic injections of L-NAME $(75 \mathrm{mg} / \mathrm{kg})$ indicate that slightly greater inhibition of NO synthase was achieved $(96 \%)$. However, our assay shows that a single injection is indeed sufficient to produce a near-complete inhibition of the enzyme in hippocampus.

However, it must be recognized that L-NAME would have been active both peripherally and centrally. Evidence that L-NAME was active in inhibiting NO synthase peripherally derives from our observation that there was a dramatic increase in blood pressure sustained throughout the period $(>60 \mathrm{~min}$ ) for which electrophysiological observations were made. L-NAME also caused measurable changes in baseline field potentials in the same animals that failed to show a blockade of LTP (experiment 6), but we are unable to comment on whether this was primarily a central or peripheral effect.

\section{Is the strength of the tetanic stimuli used to induce LTP of importance in detecting a blockade by L-NAME?}

Following the reports that inhibition of NO synthase blocked LTP in vitro (Böhme et al., 1991; O’Dell et al., 1991; Schuman and Madison, 1991; Haley et al., 1992), we were surprised at our initial finding (experiment 2) that in vivo LTP induced by strong tetanic stimuli was unaffected by high doses of L-NAME ( 75 and $750 \mathrm{mg} / \mathrm{kg}$ ). This, however, may have been due to the fact that the tetanus uscd was strong enough to recruit alternative cellular mechanisms that may be sufficient to induce potentiation independent of NO. We therefore wondered whether LTP would be blocked by L-NAME if and only if a near-threshold tetanic stimulus was used for its induction, a stimulus that, arguably, could be more physiologically relevant (Chetkovich et al., 1993; Haley et al., 1993). NO may, for example, have a role in setting the threshold for the establishment of LTP. The first experiment examining the effects of weak tetanic stimuli (experiment 3) gave suggestive results, but following the finding that LTP induction was unaffected in rats chronically treated with L-NAME (experiment 4), and the observation that several L-NAME-treated rats showed post-LTP field potentials well below the baseline (experiment 3 ), an analysis was conducted of the effects of L-NAME upon an extended nontetanized baseline (experiment 5). This revealed a gradual decline in the baseline in L-NAME-treated rats that was measurable over $1-2 \mathrm{hr}$ but not detectable over shorter baseline periods of 10-20 min beginning about an hour after the drug injection. However, taken together with the gradually increasing baseline shown by controls, the change in the dentate field potentials of the two groups over 1-2 hr seemed to be sufficient to account for the apparent inhibition of LTP induced by a weak tetanus in experiment 3 . Moreover, the critical further experiment, in which recordings were made from both a tetanized and nontetanized hemisphere within the same animal, provided strong evidence for this possibility. Our findings, therefore, offer no support for the intuition that inhibition of NO synthase may be more effective in blocking LTP in dentate gyrus in vivo with weak tetanic stimuli.

\section{Why does acute L-NAME induce changes in baseline field potentials?}

An acute injection of L-NAME resulted in a prolonged, gradual decrease in the size of the field EPSP which was preceded by a small transient rise. These changes were surprising because experiments conducted in hippocampal slices demonstrate no significant effect of NO synthase inhibitors on baseline synaptic responses (Haley et al., 1993). This suggests that the decline in evoked potentials seen reliably in the dentate gyrus following L-NAME injection in vivo is either (1) a property of networks of neurons too large to be preserved in slices, for example, those providing cholinergic or catecholaminergic afferents to the hippocampus that may be regulated by the release of NO (Hanbauer et al., 1992; Lonart et al., 1992; Wood et al., 1992), or (2) a direct or indirect effect of changes in cerebral blood flow.

In contrast to the decrease in the size of field EPSPs that follows injection of L-NAME, animals that received injections of saline showed a small increase. One possible explanation to account for this phenomenon, which has been observed previously (Bliss and Lomo, 1973), is that the level of anesthetic (urethane) may decrease slightly over time, resulting in a gradual increase in the level of synaptic transmission. Alternatively, the rising baseline may be explained by the gradual recovery of brain tissue disturbed during electrode implantation. The gradual rise in the size of the field EPSP is unlikely to be due to an increase in brain temperature as (1) core temperature was maintained at $36.2 \pm 0.2^{\circ} \mathrm{C}$ throughout recording, and (2) no corresponding decrease in the size of the population spike was observed (data not shown; Moser et al., 1993).

\section{What are the implications of L-NAME uncoupling cerebral blood flow and glucose metabolism?}

The results of this study confirm previous observations that inhibition of NO synthase in vivo results in reductions in cerebral blood flow which are not confined to specific anatomical or functional systems (Tanaka et al., 1991). However, it is unclear from previous studies whether decreases in the perfusion of brain tissue are the result of a direct vascular effect or are a secondary consequence of decreases in underlying metabolic demand (Des Rosiers et al., 1974). We have shown that the ratio of blood flow to glucose use is decreased following L-NAME in every region of the hippocampus and cerebellum examined. This suggests a direct vascular effect of NO synthase inhibition in eliciting a vasoconstriction-induced decrease in blood flow in the absence of any significant change in metabolic demand. Goadsby et al. (1992) have also reported that NO couples cerebral blood flow and metabolism.

This uncoupling may contribute to the L-NAME-induced decrease in the baselinc, although it is not clear what the consequences of the relative oligemia that develops following L-NAME treatment may be for the maintenance of normal hippocampal function. While the level of blood flow in hippocampus (and cerebellum) remains considerably higher than that which would be expected to produce hypoxic dysfunction or ischemic damage (Siesjo, 1978), and at normal levels of perfusion there is considerable excess in the delivery of energy substrates, the resulting oligaemia may be sufficient to alter 
normal synaptic transmission (e.g., size of the baseline field EPSP).

\section{Why does L-NAME have little effect in chronically treated animals?}

Treatment with L-NAME over the course of several days should afford ample opportunity for synaptic transmission to stabilize at a new lower baseline. Further injection of L-NAME would not be expected to produce additional decrements in the slope of the field potentials - as we found (experiment 5). Thus, if the apparent blockade of weak tetanus LTP seen in experiment 3 were really an artifact of a gradually changing baseline, one would not expect such LTP to be impaired in chronically treated animals. This result is exactly what was obtained (experiment 4). An alternative possible explanation for the failure to block LTP following chronic administration of L-NAME in terms of developing tolerance seems unlikely in the light of our own and Dwyer et al.'s (1991) data, showing that the level of NO synthase inhibition increases with repeated injections.

\section{Why does $L-N A M E$ fail to block dentate LTP in vivo?}

Our findings, together with those of Barnes et al. (1994), indicate that inhibition of NO synthase fails to block dentate LTP in vivo. There are at least three possible explanations for the absence of a blockade of LTP with systemic administration of an NO synthase inhibitor. First, residual NO synthase activity (4$7 \%$ in our case) may be sufficient to support normal LTP. While there are as yet no pharmacological means to ensure complete blockade of NO synthase activity, gene knockout experiments of brain NO synthase may provide such an opportunity (Huang et al., 1993). Second, NO may play a threshold modulatory role in LTP induction such that other messengers (e.g., CO, Stevens and Wang, 1993; arachadonic acid, Williams et al., 1989) could contribute to the induction of potentiation under these experimental conditions. Third, NO may have no role in the induction of LTP in vivo.

With respect to the last alternative, although several laboratories have reported that NO synthase inhibition blocks the induction of LTP, others have suggested that this effect is dependent upon experimental conditions (e.g., temperature, age of the animal, tetanus parameters; Gribkoff and Lum-Ragan, 1992; Chetkovich et al., 1993; Haley et al., 1993; Williams et al., 1993). It is not, therefore, altogether unprecedented that the further procedural differences of this study (e.g., in vivo vs in vitro, systemic administration vs bath application) have resulted in no block of LTP. A separate consideration is the use of the perforant path-dentate gyrus synapse rather than the Schaffer collateral-CAl synapse used more frequently in hippocampal slices. We chose to study synapses in the dentate gyrus because they exhibit a relatively high density of NO synthase (Bredt et al., 1990, 1991), and because this is a frequently used and reliable method of studying hippocampal LTP in vivo. In addition, there are no a priori grounds to believe that LTP in perforant path-dentate gyrus synapses is fundamentally different from that of Schaffer collateral-CAl synapses (e.g., NMDA receptor dependency). Even so, we cannot rule out the possibility that our results may not apply to other hippocampal subfields, and a study of CA1 LTP in vivo would be worthwhile.

Recent studies by Mizutani et al. (1993) and Iga et al. (1993) report that infusion of L-NAME into the lateral ventricle blocks the induction of LTP of the population spike in the dentate gyrus in vivo. Our data (experiment 6) does not show any block- ade of LTP either in terms of the slope of the field EPSP or of the population spike. There are at least two differences in procedure that may account for these anomolous results. First, the strain and age of the animals may be relevant. Second, the intracerebroventricular route of administration of the drug may result in higher levels of enzyme inhibition in the hippocampus than the $>95 \%$ inhibition we achieved. In addition, it should be noted that Mizutani et al. (1993) report significantly smaller initial potentiation in animals treated with NO synthase inhibitors, which is in contrast to most other studies measuring EPSPs both in vitro and in vivo, and raises the possibility that intracerebroventricular administration may have additional physiological effects. Further investigations are underway in our laboratory.

\section{Can L-NAME induce apparently greater LTP?}

One intriguing observation of experiment 6 was that the level of long-lasting synaptic potentiation in L-NAME-treated animals appeared to be greater than in control animals when expressed as a ratio of tetanized to nontetanized hemispheres. Although this effect was not significant $(p=0.07)$, there is a clear trend suggesting an L-NAME-induced enhancement of LTP. Because NO can block NMDA receptors (Izumi et al., 1992; Lei et al., 1992; Manzoni et al., 1992), inhibition of NO synthase may result in more NMDA receptor activation during the tetanus and thus elicit greater or more long-lasting potentiation. The magnitude of such an effect may vary as a function of the extent of NMDA receptor activation and thus be determined by the size of the tetanus. Interestingly, we did not observe any trend toward greater LTP in experiment 1 , in which a strong tetanus was used. However, the results of experiment 1 are plotted without taking into account any differential changes in the baseline that might have occurred in saline and L-NAMEtreated rats (for which we have no data because all animals were tetanized). If changes similar to those measured in experiment 5 occurred in experiment 1 , the LIP shown by the L-NAME group is likely to have been greater than that of the saline group. Wc do not, however, scck to overcmphasize this enhanced LTP phenomenon: the effect did not reach statistical significance and is calculated in the presence of gradually changing baselines in both the L-NAME and saline groups. Further study seems warranted.

\section{What are the implications for behavioral studies?}

There are several reports in the literature indicating that NO synthase inhibitors impair performance in a variety of learning paradigms including tasks thought to require the integrity of the hippocampus (Chapman et al., 1992; Hölscher and Rose, 1992; Böhme et al., 1993). Although it is by no means certain if, and to what extent, the mechanisms of LTP may also be involved in learning, the lack of an effect of L-NAME on the induction of hippocampal LTP in vivo would appear to call into question whether NO synthase inhibition is producing a learning impairment through an effect on LTP. This does not, however, preclude the possibility that NO synthase inhibition is interfering with some other aspect of hippocampal physiology (Hanbauer et al., 1992; Lonart et al., 1992; Wood et al., 1992) which may result in a spatial learning impairment, or changes in brain function elsewhere which may account for apparent impairments of other types of learning. It is unclear to what extent the L-NAME-induced reduction in the size of dentate field EPSPs would affect the normal function of the hippocampus or other 
brain areas. A detailed investigation into the effects of NO synthase inhibitors on various forms of learning in the watermaze is reported in the preceding article (Bannerman et al., 1994).

\section{References}

Bannerman DM, Chapman PF, Kelly PAT, Butcher SP, Morris RGM (1994) Inhibition of nitric oxide synthase does not impair spatial learning. J Neurosci 14:7404-7414.

Barnes CA, McNaughton BL, Bredt DS, Ferris CD, Snyder SH (1994) Nitric oxide synthase inhibition in vivo: lack of effect on hippocampal synaptic enhancement or spatial memory. In: Long-term potentiation: a debate of current issues, Vol 2 (Baudry M, Davis J, eds). In press.

Bekkers JM, Stevens CF (1990) Presynaptic mechanism for long-term potentiation in the hippocampus. Nature 346:724-729.

Bliss TVP, Collingridge GL (1993) A synaptic model of memory: longterm potentiation in the hippocampus. Nature 361:31-39.

Bliss TVP, Lømo T (1973) Long-lasting potentiation of synaptic transmission in the dentate area of anaesthetized rabbit following stimulation of the perforant path. J Physiol (Lond) 232:331-356.

Böhme GA, Bon C, Stutzmann J-M, Doble A, Blanchard JC (1991) Possible involvement of nitric oxide in long-term potentiation. Eur J Pharmacol 199:379-381.

Böhme GA, Bon C, Lemaire M, Reibaud M, Piot O, Stutzmann J-M, Doble A, Blanchard JC (1993) Altered synaptic plasticity and memory formation in nitric oxide synthase inhibitor-treated rats. Proc Natl Acad Sci USA 90:9191-9194.

Bon C, Böhme GA, Doble A, Blanchard JC (1992) A role for nitric oxide in long-term potentiation. Eur J Neurosci 4:420-424.

Bonhoeffer T, Staiger V, Aertsen A (1989) Synaptic plasticity in rat hippocampal slice cultures: local "Hebbian" conjuction of pre- and postsynaptic stimulation leads to distributed synaptic enhancement. Proc Natl Acad Sci USA 86:8113-8117.

Bredt DS, Snyder SH (1990) Isolation of nitric oxide synthetase, a calmodulin requiring enzyme. Proc Natl Acad Sci USA 87:682-685.

Bredt DS, Snyder SH (1992) Nitric oxide, a novel neuronal messenger. Neuron 8:3-11.

Bredt DS, Hwang PM, Snyder SH (1990) Localization of nitric oxide synthase indicating a neural role for nitric oxide. Nature 347:768770.

Bredt DS, Glatt CE, Hwang PM, Fotuhi M, Dawson TM, Snyder SH (1991) Nitric oxide synthase protein and mRNA are discretely localised in neuronal populations of the mammalian CNS together with NADPH diapherase. Neuron 7:615-624.

Chapman PF, Atkins CM, Allen MT, Haley JE, Steinmetz JE (1992) Inhibition of nitric oxide synthesis impairs two different forms of learning. Neuroreport 3:567-570.

Chetkovich DM, Klann E, Sweatt JD (1993) Nitric oxide synthaseindependent long-term potentiation in area $\mathrm{CAl}$ of hippocampus. Neuroreport 4:919-922.

Collingridge GL, Kehl SJ, McLennan H (1983) Excitatory amino acids in synaptic transmission in the Schaffer collateral-commissural pathway of the rat hippocampus. J Physiol (Lond) 334:33-46.

DesRosiers MH, Kennedy C, Patlak CS, Pettigrew KD, Sokoloff L, Reivich M (1974) Relationships between local cerebral blood flow and glucose utilization in the rat. Neurology 14:389-396.

Dolphin A, Errington ML, Bliss TVP (1982) Long-term potentiation of the perforant path in vivo is associated with increased glutamate release. Nature 297:496-498.

Dwyer MA, Bredt DS, Snyder SH (1991) Nitric oxide synthase: irreversible inhibition by $\mathrm{L}-N^{\mathrm{G}}$-nitroarginine in brain in vitro and in vivo. Biochem Biophys Res Commun 176:1136-1141.

Garthwaite J, Charles SL, Chess-Williams R (1988) Endotheliumderived relaxing factor release on activation of NMDA receptors suggests role as intercellular messenger in the brain. Nature 336:385388.

Goadsby PJ, Kaube H, Hoskin KL (1992) Nitric oxide synthesis couples cerebral blood flow and metabolism. Brain Res 595:167-170.

Gribkoff V, Lum-Ragan J (1992) Differential effect of two forms of tetanic stimulation of NOS-inhibitor-dependent LTP. J Neurophysiol 68:639-642.

Haley JE, Wilcox GL, Chapman PF (1992) The role of nitric oxide in hippocampal long-term potentiation. Neuron 8:211-216.

Haley JE, Malen PL, Chapman PF (1993) Nitric oxide synthase inhibitors block long-term potentiation induced by weak but not strong tetanic stimulation at physiological brain temperatures in rat hippocampal slices. Neurosci Lett, in press.

Hanbauer I, Wink D, Osawa Y, Edelman GM, Gally JA (1992) The role of nitric oxide in NMDA-evoked release of [ $\left.3^{\mathrm{H}}\right]$-dopamine from striatal slices. Neuroreport 3:409-412.

Hölscher C, Rose SPR (1992) An inhibitor of nitric oxide synthesis prevents memory formation in the chick. Neurosci Lett 145:165-167.

Huang PL, Dawson TM, Bredt DS, Snyder SH, Fishman MC (1993) Targeted disruption of the neuronal nitric oxide synthase gene. Cell 75:1273-1286.

Iga $Y$, Yoshioka M, Togashi H, Saito H (1993) Inhibitory action of $N^{\omega}$-nitro-L-arginine methyl ester on in vivo long-term potentiation in the rat dentate gyrus. Eur J Pharmacol 238:395-398.

Izumi Y, Clifford DB, Zorumski CF (1992) Inhibition of long-term potentiation by NMDA-mediated nitric oxide release. Science 257 : 1273-1276.

Kelso SR, Ganong AH, Brown TH (1986) Hebbian synapses in hippocampus. Proc Natl Acad Sci USA 83:5326-5330.

Lei SZ, Pan ZH, Aggarwal SK, Chen HSV, Hartman J, Sucher NJ, Lipton SA (1992) Effect of nitric oxide production on the redox modulatory site of the NMDA receptor-channel complex. Neuron 8:1087-1099.

Lonart G, Wang J, Johnson KM (1992) Nitric oxide induces transmitter release from hippocampal slices. Eur J Pharmacol 220:271272.

Malenka RC (1991) Postsynaptic factors control the duration of synaptic enhancement in area CA1 of the hippocampus. Neuron 6:5360 .

Malinow R, Tsien RW (1990) Presynaptic enhancement shown by whole-cell recordings of long-term potentiation in hippocampal slices. Nature 346:177-180.

Manzoni O, Prezau L, Marin P, Deshager S, Bockaert J, Fagni L (1992) Nitric oxide-induced blockade of NMDA receptors. Neuron 8:653662.

McNaughton BL, Douglas RM, Goddard GV (1978) Synaptic enhancement in the fascia dentata: cooperativity among coactive elements. Brain Res 157:277-293.

Mizutani A, Saito II, Abe K (1993) Involvement of nitric oxide in long-term potentiation in the dentate gyrus in vivo. Brain Res 605: 309-311.

Moncada S (1992) Nitric oxide gas-mediator, modulator, and pathophysiologic entity. J Lab Clin Med 120:187-191.

Morris RGM, Davis S, Butcher SP (1990) Hippocampal synaptic plasticity and NMDA receptors: a role in information storage? Philos Trans R Soc Lond [Biol] 329:187-204.

Moser E, Mathiesen I, Andersen P (1993) Association between brain temperature and dentate field potentials in exploring and swimming rats. Science 259:1324-1326.

O'Dell TJ, Hawkins RD, Kandel ER, Arancio O (1991) Tests of the roles of two diffusable substances in long-term potentiation-evidence for nitric oxide as a possible early retrograde messenger. Proc Natl Acad Sci USA 88:11285-11289.

Sakurada O, Kennedy C, Jehle J, Brown JD, Carbin GL, Sokoloff L (1978) Measurement of cerebral blood flow with iodo-[ $\left[{ }^{14} \mathrm{C}\right]$-antipyrine. Am J Physiol 234:H59-H66.

Schuman EM, Madison DV (1991) A requirement for the intercellular messenger nitric oxide in long-term potentiation. Science 254:15031506.

Sharkey J, McBean DE, Kelly PAT (1991a) Acute cocaine administration: effects on local cerebral blood flow and metabolic demand in the rat. Brain Res 548:310-314.

Sharkey J, McBean DE, Ritchie IM, Kelly PAT (1991b) Normal cerebrovascular regulatory mechanisms are present in intracerebral neuronal transplants. Neuroscience 41:703-711.

Siesjö BK (1978) Brain energy metabolism. Chichester: Wiley.

Sokoloff L, Reivich M, Kennedy C, DesRosiers MH, Patlak CS, Pettigrew KD, Sakurada O, Shinohara M (1977) The $\left[{ }^{14} \mathrm{C}\right]$-deoxyglucose method for the measurement of local cerebral glucose utilization: theory, procedure and normal values in the conscious and anaesthetized albino rat. J Neurochem 28:897-916.

Stevens CF, Wang Y (1993) Reversal of long-term potentiation by inhibitors of haem oxygenase. Nature 364:147-149.

Tanaka K, Gotoh F, Gomi S, Takashima S, Nihara T, Shirai T, Nogawa S, Nagata E (1991) Inhibition of nitric oxide synthesis induces a significant reduction in local cerebral blood flow in the rat. Neurosci Lett 127:129-132. 
Wigstrom H, Gustafsson B, Huang Y-Y, Abraham WC (1986) Hippocampal long-lasting potentiation is induced by pairing single afferent volleys with intra-cellularly injected depolarizing current pulses. Acta Physiol Scand 126:317-319.

Williams JH, Errington ML, Lynch MA, Bliss TVP (1989) Arachidonic acid induces a long-term activity-dependent enhancement of synaptic transmission in the hippocampus. Nature 341:739-742.

Williams JH, Li Y-G, Nayak A, Errington ML, Murphy KPSJ, Bliss TVP (1993) The suppresion of long-term potentiation in rat hip- pocampus by inhibitors of nitric oxide synthase is temperature and age dependent. Neuron 11:877-884.

Wood PL, Ryan R, Li M (1992) Excitatory amino acid signal transduction in the hippocampus: role of noradrenergic afferents and nitric oxide in cGMP increases in vivo. Life Sci 51:601-606.

Zhuo M, Small SA, Kandel ER, Hawkins RD (1993) Nitric oxide and carbon monoxide produce activity-dependent long-term synaptic enhancement in hippocampus. Science 260:1946-1950. 